\title{
Análise Multitemporal do Uso e Ocupação do Solo no Corredor Ecológico do Rio Pacoti (Ceará) nos anos de 1985, 2000 e 2015
}

\author{
Multitemporal Analysis of the Occupation and Utilization of the Soil in the Ecological \\ Corridor of the Pacoti River (Ceará) in 1985, 2000 and 2015
}

\section{Análisis Multitemporal del Uso y Ocupación de Suelos en el Corredor Ecológico del Río Pacoti (Ceará) en 1985, 2000 y 2015}

\author{
Thatiane Maria Souza de Araújo ${ }^{1}$ \\ Frederico de Holanda Bastos² \\ Francisco Davy Braz Rabelo ${ }^{3}$
}

\begin{abstract}
RESUMO: Estudos relacionados à caracterização temporal do uso e ocupação do solo são indispensáveis para a definição de políticas públicas de ordenamento territorial, permitindo compreender a dinâmica de ocupação. Portanto, o objetivo deste trabalho foi mapear as formas de uso e ocupação do Corredor Ecológico do Rio Pacoti (Ceará) em diferentes anos com o intuito de verificar sua evolução e se ele cumpre seu papel de conectividade. Os mapas da cobertura do solo foram obtidos por meio da classificação de imagens de satélite do programa Landsat, operações 5 e 8, nos respectivos sensores Thematic Mapper (TM) e Operational Land Imager (OLI), e levantamentos de campo. Os resultados demonstraram que houve uma diminuição expressiva da classe solo exposto de 1985 ao ano 2000 e aumento da vegetação entre os anos de 1985 a 2015. Considera-se com esses resultados que a manutenção do corredor ecológico tem sido efetiva entre os anos estudados.
\end{abstract}

PALAVRAS-CHAVE: Efetividade do corredor ecológico. Conservação biológica. Ocupação espaçotemporal.

\begin{abstract}
Studies related to the temporal characterization and occupation of the soil are fundamental for the definition of public policies of territorial planning, allowing to comprehend the dynamics of occupation. Therefore, the objective of this article was to map the forms of utilization and occupation of the Ecological Corridor of the Pacoti River (Ceará) in different years in order to verify its evolution and if it fulfills its connectivity role. The groundcover maps were obtained by the classification of satellite images of the Landsat program, operations 5 and 8, in the respective sensors Thematic Mapper (TM) and Operational Land Imager (OLI), and field surveys. The results showed that there was a significant

\footnotetext{
1 Universidade Estadual do Ceará (UECE). Rua Antônio Bandeira, 513, Ap 103, Bloco A, Itaperi. Fortaleza - CE. CEP: 60.714-170. E-mail: thatianemsa@yahoo.com.br.

${ }^{2}$ Universidade Estadual do Ceará (UECE). Programa de Pós-Graduação em Geografia. Av. Dr. Silas Munguba, 1700, Campus do Itaperi, CEP: 60.714-903. Fortaleza/CE. E-mail: fred.holanda@uece.br.

${ }^{3}$ Universidade Federal do Ceará (UFC). Campus do Pici - Bloco 911 - CEP 60440-554 - Fortaleza - CE. Email: davyrabelo@yahoo.com.br.
} 
decrease of the exposed soil from 1985 to 2000 and an increase of vegetation between 1985 and 2015 . The maintenance of the ecological corridor has been effective between the years studied, according to the results obtained.

KEYWORDS: Ecological corridor effectiveness. Biological conservation. Spatiotemporal variation.

RESUMEN: Los estudios relacionados con la caracterización temporal del uso y ocupación del suelo son indispensables para la definición de políticas públicas de planificación territorial, permitiendo comprender la dinámica de la ocupación. Por lo tanto, el objetivo de este artículo fue mapear las formas de uso y ocupación del Corredor Ecológico del río Pacoti (Ceará) en diferentes años para verificar su evolución y si cumple con su rol de conectividad. Los mapas de cobertura del suelo se obtuvieron mediante la clasificación de imágenes satelitales del programa Landsat, operaciones 5 y 8, en los sensores respectivos Thematic Mapper (TM) y Operational Land Imager (OLI), y estudios de campo. Los resultados mostraron que hubo una disminución significativa de suelo expuesto de 1985 a 2000 y un aumento de la vegetación entre 1985 y 2015. Se considera con estos resultados que la manutención del corredor ecológico ha sido efectiva entre los años estudiados.

PALABRAS-CLAVE: Eficacia del corredor ecológico. Conservación biológica. Variación espaciotemporal.

\section{INTRODUÇÃO}

A análise da paisagem em regiões intensamente fragmentadas é de fundamental importância para o estabelecimento de modelos de conservação da biodiversidade por determinar o grau de comprometimento ecológico da área em análise e também avaliar em que grau de efetividade encontra-se determinada área.

O Corredor Ecológico do Rio Pacoti tem a função de conectar dois grandes remanescentes de Floresta Atlântica dentro do Domínio das Caatingas no Estado do Ceará. Entre as extremidades da Serra de Baturité, considerada como uma ilha de umidade dentro do contexto regional (BASTOS; CORDEIRO; SILVA, 2017), até o mangue da Foz do Rio Pacoti. Entre esses dois remanescentes, a área do corredor passa por uma variedade de ambientes que a torna peculiar. No alto curso do Rio Pacoti observa-se a presença de vegetação de grande porte, composta por remanescentes da Mata Atlântica, já em seu médio curso constata-se a existência de espécies vegetais transicionais da floresta úmida para a caatinga (CEARÁ, 2017b), considerando que as formações florísticas variam de acordo com as condições de solo, clima, temperatura, umidade, topografia e influências antrópicas existentes em cada trecho.

A escolha do Corredor Ecológico do Rio Pacoti como área de estudo deve-se à sua grande importância estratégica para o Estado do Ceará, sendo uma das principais fontes de abastecimento de água para a região. Destaca-se ainda por abrigar parte dos últimos remanescentes de Mata Atlântica nas áreas de maiores altitudes, com vegetações em diferentes estados de conservação (CAVALCANTE, 2005). 
Contiguidade de fragmentos não necessariamente determina a existência de conectividade, pois ela pode existir sem que haja a continuação dos fragmentos (NOVELLI; SILVA, 2013). Porém, avaliar as mudanças que ocorreram na cobertura vegetal presente na área do corredor ecológico numa perspectiva de conservação dos recursos naturais existentes pode trazer resultados satisfatórios para subsidiar o planejamento ambiental da área. Desse modo, a análise multitemporal do uso e cobertura da terra em anos diferentes é importante para analisar as classes de uso do solo para um melhor planejamento e organização de ocupação de uma determinada área. Assim, utiliza-se das técnicas de Sensoriamento Remoto e Sistemas de Informação Geográfica (SIG), onde é possível realizar o monitoramento de forma prática, e obter informações para avaliar a dinâmica da paisagem (NOVO, 2008), através do uso de imagens de satélite. O mapeamento de uso da terra contribui para o acervo de conhecimentos sobre determinada área e, aliado aos mapeamentos geológicos, geomorfológicos, pedológicos e da cobertura vegetal, podem indicar o nível de sustentabilidade de uma área, fornecendo assim subsídios para avaliações dos impactos ambientais em diversos níveis de intensidade (IBGE, 1999).

\section{LOCALIZAÇÃO E CARACTERIZAÇÃO DA ÁREA DE ESTUDO}

O Corredor Ecológico do Rio Pacoti possui uma área de 19.405 .00 hectares e um perímetro de 28,128 quilômetros. Localiza-se entre as coordenadas planas UTM X: 566589 e Y: 95688588 UTM X: 514700 e Y: 9534359 . A área de estudo (Figura 1) faz parte da Região Metropolitana de Fortaleza - RMF, setor litorâneo do Ceará, abrangendo parte da vertente úmida da Serra de Baturité. Sua delimitação segue a extensão do afluente principal do Rio Pacoti, da nascente à foz e nas faixas marginais em ambas às margens do rio no trecho que vai da ponte velha da CE-040 (fim da APA do Rio Pacoti) até a cota 600 metros da Serra de Baturité (início da APA da Serra de Baturité) abrangendo parte dos municípios de Aquiraz, Itaitinga, Pacatuba, Guaiúba, Palmácia, Pacoti, Horizonte, Pacajus, Acarape e Redenção (CEARÁ, 2017b).

A Região Metropolitana de Fortaleza é uma área de transição entre regimes climáticos semiáridos e subúmidos. A pluviosidade média nessa área é de 942,6 milímetros com temperatura média anual de $26^{\circ} \mathrm{C}$, chuvas concentradas de janeiro a junho, e potencial de evapotranspiração superior à precipitação (NIMER, 1972). Já a Serra de Baturité possui características climáticas que condicionam a diversidade fisiográfica existente nessa região, sendo resultado da ação combinada do relevo e altitude, direção dos ventos e distância do litoral, produzindo um dos maiores totais pluviométricos do Estado do Ceará (BASTOS, 2012; BASTOS; CORDEIRO; SILVA, 2017; BÉTARD; PEULVAST; CLAUDINO-SALES, 2007). 
Figura 1 - Localização da área de estudo

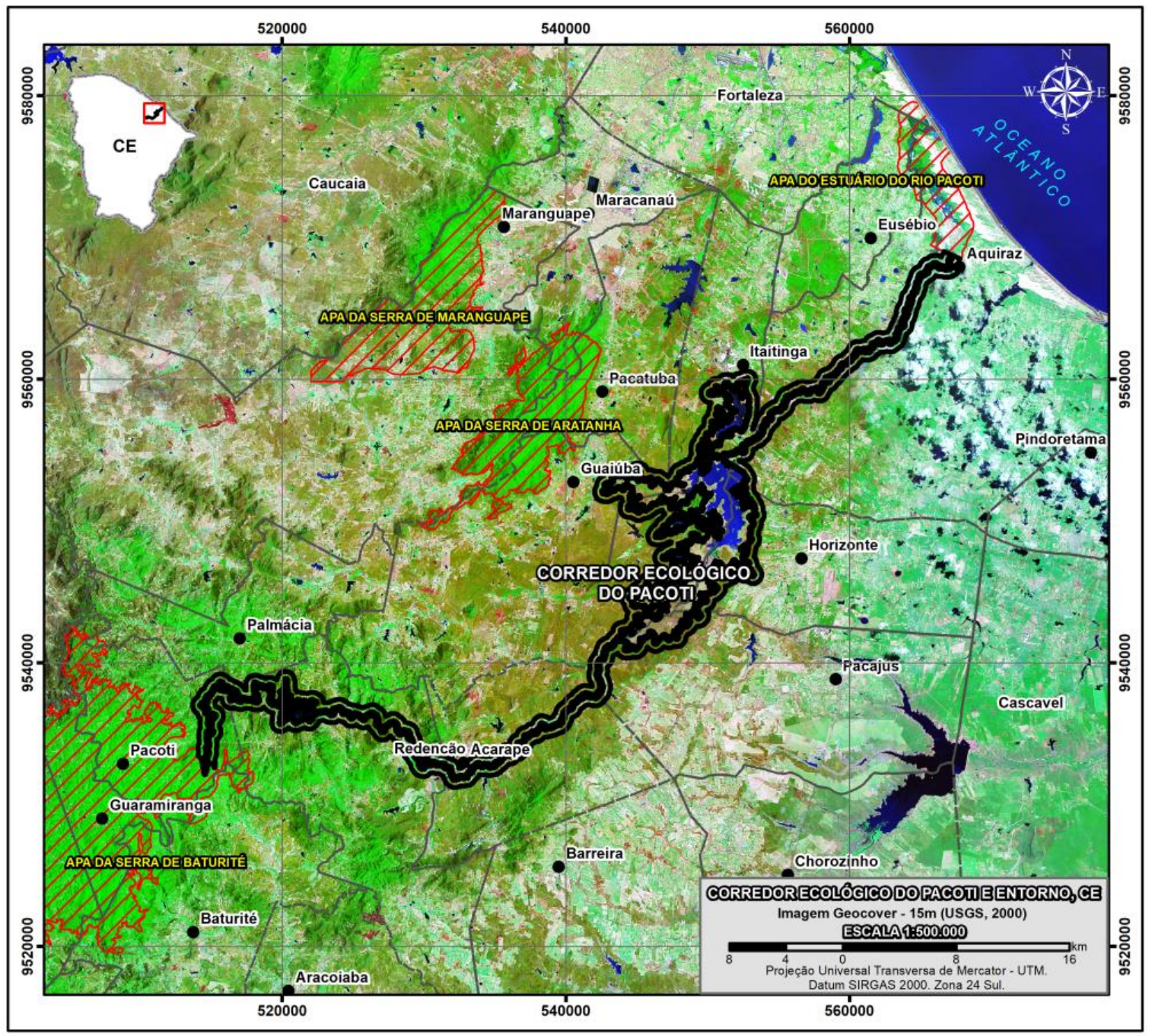

Fonte: Araújo (2019).

\section{METODOLOGIA}

Para realização da análise multitemporal da cobertura do solo no Corredor Ecológico do Rio Pacoti foram selecionadas duas imagens do satélite Landsat 5, sensor Thematic Mapper (TM) e uma do Landsat 8, sensor Operational Land Imager (OLI), compreendendo o recorte temporal de 1985, 2000 e 2015 (Tabela 1). A escolha justifica-se pela disponibilidade gratuita através do (INPE) Instituto Nacional de Pesquisas Espaciais. As datas das imagens foram selecionadas visando escolher os períodos com o mínimo de nebulosidade possível, mantendo um padrão temporal em relação aos períodos de imageamento.

Os anos foram selecionados considerando-se o histórico de ocupação do corredor e, principalmente, a viabilidade de tratamento das imagens para a realização do trabalho. As imagens de satélite foram selecionadas em função da menor presença de nuvens, sendo aceito, segundo Prado, Novo e Pereira (2007), 35\% ou menos da imagem coberta por nuvens. 
Tabela 1 - Principais características das imagens utilizadas nesse estudo

\begin{tabular}{c|c|c|c}
\hline Satélite & Sensor & Data & Resolução espectral \\
\hline LANDSAT 5 & TM & 21-AUG-1985 & $30 \mathrm{~m}$ \\
\hline LANDSAT 5 & TM & 14-AUG-2000 & $30 \mathrm{~m}$ \\
\hline LANDSAT 8 & OLI & 08-AUG-2015 & $30 \mathrm{~m}$ \\
\hline
\end{tabular}

Fonte: Instituto Nacional de Pesquisas Espaciais (2019).

Para o tratamento e classificação das imagens foi utilizado o programa ArcGIS $\AA_{10} 10.2$, aplicando técnicas de processamento digital de imagem, seguindo as etapas de préprocessamento, através da calibração e correção geométrica das imagens, realce, por meio da manipulação do histograma permitindo melhor descriminação dos alvos e, por fim, classificação, através do método supervisionado com o algoritmo de Máxima Verossimilhança (CRÓSTA, 1992).

No processo de classificação, foi realizada a coleta de amostras da imagem (agrupamento de pixels), baseadas nas classes de uso do solo, utilizando como critério a homogeneidade dos parâmetros identificados, visando associar determinados pixels a uma classe previamente definida. No processo de amostragem buscou-se contemplar todas as variações de pixels da classe determinada, de maneira uniforme, visando maior acurácia. Para definição das classes mapeadas e as áreas utilizadas nas amostras de treinamento, teve-se um conhecimento prévio da área representada da imagem, feito por meio de visitas a campo.

Para cada ano da pesquisa $(1985,2000,2015)$, as imagens classificadas foram processadas e convertidas para o modelo vetorial. Os dados vetoriais foram editados como mapa temático para quantificação das classes temáticas (água, nuvens, solo exposto, urbano e vegetação) utilizando-se técnicas de análise espaciais, sobreposição de dados matriciais e operações métricas.

Já dentro do ambiente SIG, através do ArcGIS 10 foram criadas as amostras das classes de uso do solo utilizando como critério a homogeneidade das informações. As classes utilizadas no Mapa de Cobertura e Uso da Terra estão descritas no Quadro 1.

Para a elaboração do mapa de identificação das atividades de mineração na área de estudo, foi realizado um levantamento no site da (ANM) Agência Nacional de Mineração a partir do Sistema de Informações Geográficas da Mineração - SIGMINE, desenvolvido pela Coordenação de Geoprocessamento - CGEO/CGTIG, a qual tem como objetivo ser um sistema de referência na busca de informações atualizadas relativas às áreas dos processos minerários, associadas a outras informações geográficas de interesse ao setor. 
Quadro 1 - Classes temáticas utilizadas para a confecção do Mapa de Cobertura e Uso da Terra

\begin{tabular}{|c|c|l|}
\hline Atributos & $\begin{array}{c}\text { Classes } \\
\text { temáticas }\end{array}$ & \multicolumn{1}{c|}{ Descrição } \\
\hline $\mathbf{1}$ & Água & $\begin{array}{l}\text { Os corpos d'água continentais referem-se aos corpos d'água naturais } \\
\text { e artificiais que não são de origem marinha tais como: rios, canais, } \\
\text { lagos e lagoas de água doce, represas, açudes, etc. }\end{array}$ \\
\hline $\mathbf{2}$ & Nuvem & Nuvens da área \\
\hline $\mathbf{3}$ & $\begin{array}{c}\text { Solo } \\
\text { exposto }\end{array}$ & $\begin{array}{l}\text { Representada pela não presença de vegetação arbórea, arbustiva ou } \\
\text { gramínea, apenas o solo nu; }\end{array}$ \\
\hline $\mathbf{4}$ & Urbano & $\begin{array}{l}\text { Como situação urbana foram consideradas as áreas correspondentes } \\
\text { às cidades (sedes municipais), às vilas (sedes distritais) e às áreas } \\
\text { urbanas isoladas conforme classificação do IBGE }\end{array}$ \\
\hline $\mathbf{5}$ & Vegetação & $\begin{array}{l}\text { Vegetação de porte arbóreo, arbustivo e herbáceo composta por } \\
\text { vegetação nativa e exótica }\end{array}$ \\
\hline
\end{tabular}

Fonte: IBGE (2013).

\section{RESULTADOS E DISCUSSÃO}

Através da classificação digital supervisionada (MAXVER) foi possível analisar a distribuição espacial bem como quantificar as formas de uso e cobertura do solo no corredor ecológico do Rio Pacoti. Os resultados obtidos estão apresentados em três mapas temáticos do local, referente aos anos de 1985, 2000 e 2015. Uma análise inicial das áreas das classes de uso e cobertura, individualizada para cada cenário temporal, permitiu identificar as classes de maior dinâmica evolutiva e as classes invariantes.

Foram selecionadas cinco classes para o mapeamento, sendo elas: Água (A), Nuvens (B), Solo exposto (C), Urbano (D) e Vegetação (E). Todas foram identificadas a partir de visitas de campo para confirmação no terreno e foram definidas seguindo as orientações do Manual do Uso da Terra (IBGE, 2013).

Calcularam-se os dados a partir do mapeamento da cobertura e uso da terra do Corredor Ecológico do Rio Pacoti para o ano de 1985 e com maior percentual das classes mapeadas, apresentou-se a vegetação com 11707,91 hectares, ou seja, $72 \%$ do total mapeado, seguida de solo exposto com 3352,46 hectares e $21 \%$ da área mapeada e da área urbana com 944,17 hectares, correspondendo a $6 \%$. Água e nuvens apresentaram respectivamente um total de 105,21 hectares (Figura 2).

A distribuição das classes de uso do solo e cobertura vegetal no corredor ecológico em 2000 apresentou 14176,95 hectares e 88\% para a vegetação, 708,82 hectares e 7\% para o solo exposto, 1100,50 hectares e $4 \%$ para a classe Urbano e 124,11 hectares e $1 \%$ para a classe água (Figura 3). 
Figura 2 - Gráfico representando as classes de uso do solo e cobertura vegetal do corredor ecológico no ano de 1985

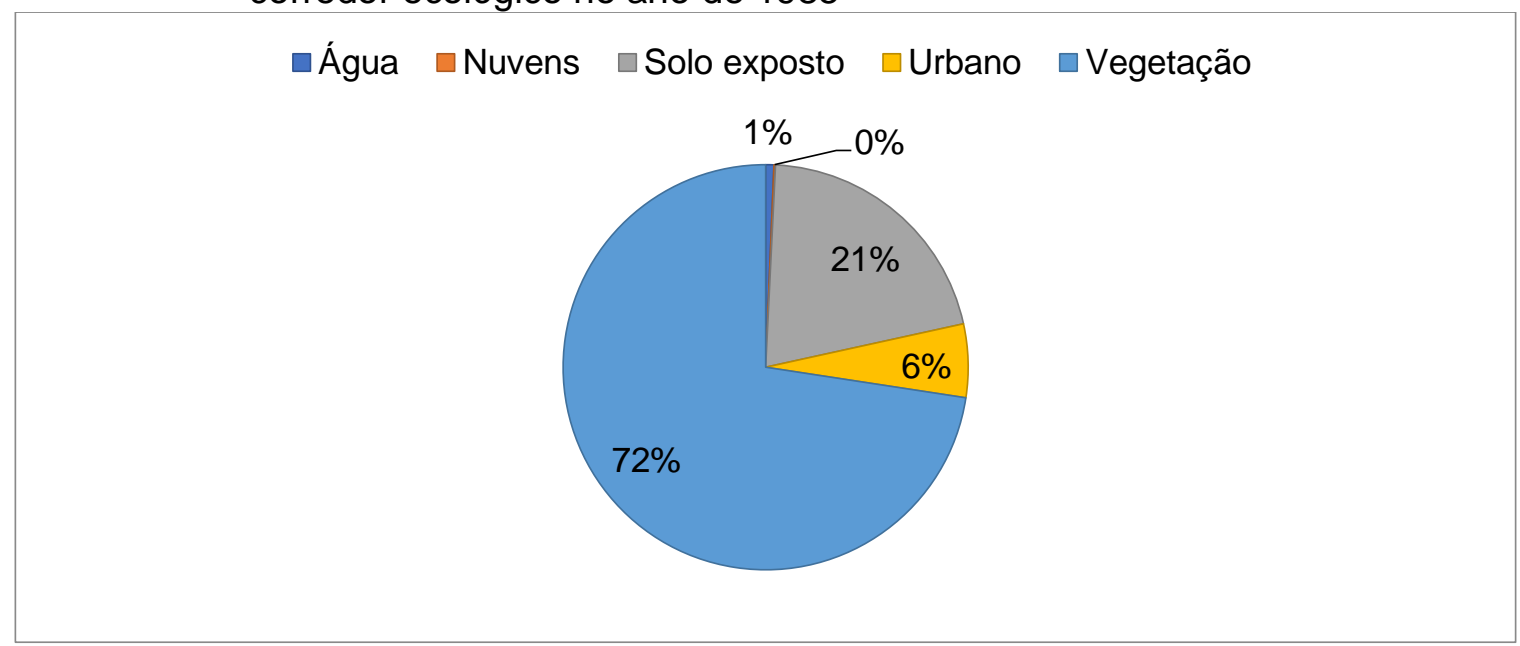

Fonte: Araújo (2019).

Figura 3 - Gráfico representando as classes de uso do solo e cobertura vegetal do corredor ecológico no ano 2000

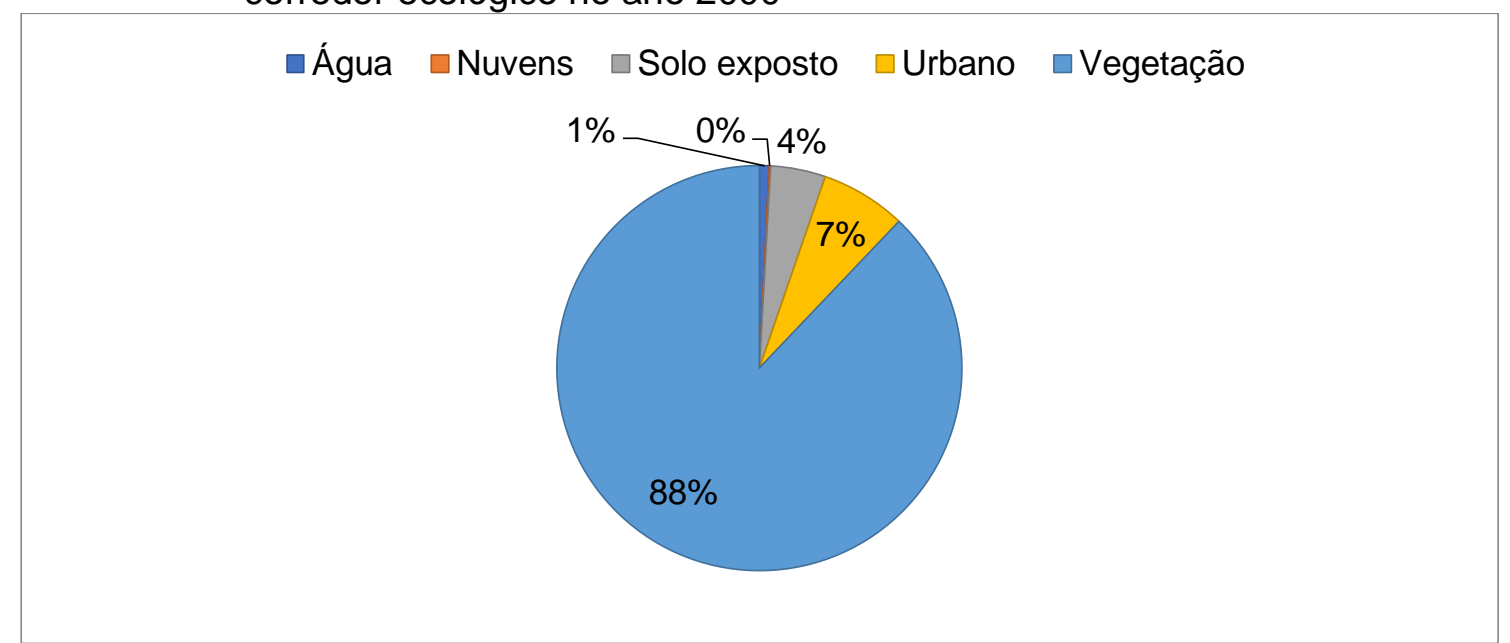

Fonte: Araújo (2019).

Os resultados do mapeamento demonstraram que a vegetação analisada nas imagens de 1985 para a de 2000 teve um acréscimo de 15,31\%, diminuindo no ano 2000 para 2015 de $2,32 \%$. Com o aumento da cobertura vegetal observa-se uma diminuição do solo exposto de $16,39 \%$ de 1985 para 2000.

Os dados do ano de 2015 apresentaram-se da seguinte forma: A classe Vegetação apresenta-se com 13803,35 hectares e 86\%; Urbano com 1046,32 hectares e 7\%, Solo exposto com 1125,36 9 hectares e 6\% e água com 141,55 hectares e 1\% (Figura 4). O mapa da Figura 5 apresenta a distribuição espacial da cobertura e uso da terra da área estudada referente aos anos de 1985, 2000 e 2015. 
Figura 4 - Gráfico representando as classes de uso do solo e cobertura vegetal do corredor ecológico no ano 2015

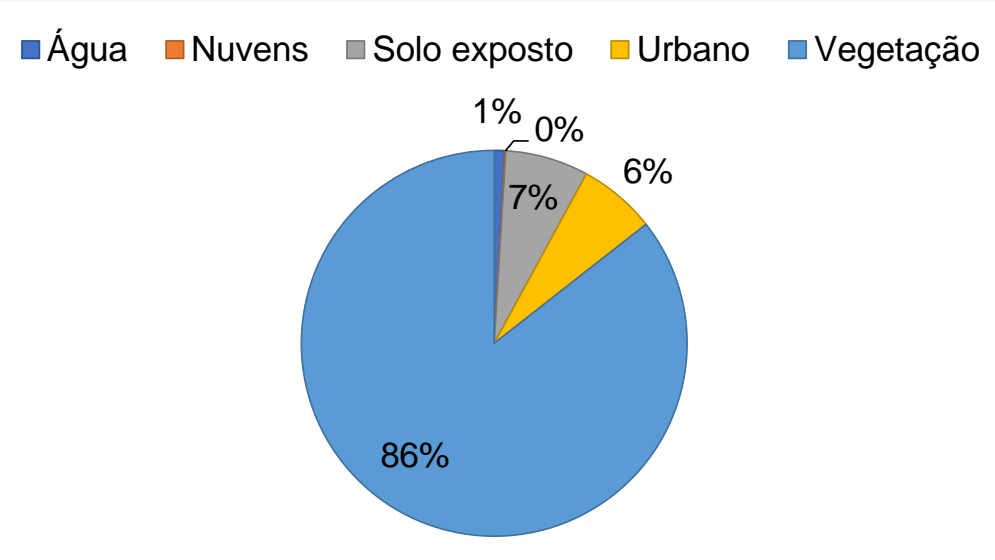

Fonte: Araújo (2019).

Figura 5 - Mapa da evolução de uso e ocupação do solo do Corredor Ecológico do rio Pacoti

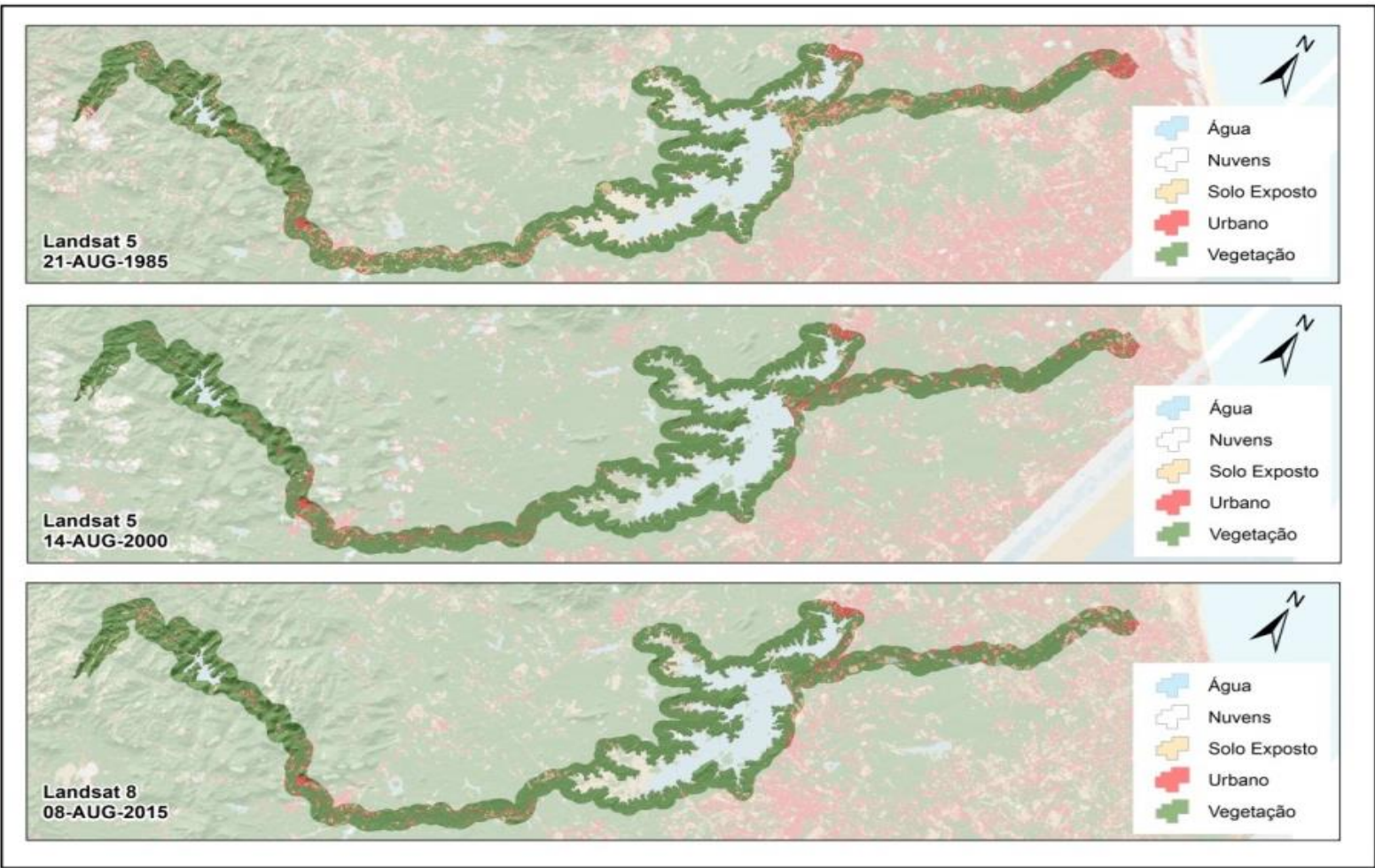

Fonte: Araújo (2019).

Após a conclusão do mapeamento da cobertura vegetal e uso da terra em diferentes períodos, 1985, 2000 e 2015, realizou-se uma análise evolutiva das alterações ocorridas na área de estudo. Os dados quantitativos referentes à evolução da cobertura e uso da terra da área destinada ao corredor ecológico encontram-se organizados na Tabela 2 e na Figura 6.

Os resultados do mapeamento demonstram que a vegetação analisada nas imagens de 1985 para a de 2000 teve um acréscimo de 15,31\%, diminuindo no ano de 2000 para 2015 
de $2,32 \%$. Com o aumento da cobertura vegetal observa-se uma diminuição do solo exposto de $16,39 \%$ de 1985 para 2000. De acordo com os dados da figura anterior, pode-se afirmar que, de modo geral, houve melhoria nos níveis de proteção vegetal na área de estudo entre os anos analisados. Isto ocorreu provavelmente devido a ocorrência de uma possível sucessão ecológica secundária, que se refletiu em melhoras na condição ambiental e que permitiu a identificação de crescimento de áreas florestadas na classificação.

Tabela 2 - Evolução e cobertura da terra nos três anos em análise

\begin{tabular}{l|c|c|c|c|c|c}
\hline \multirow{2}{*}{$\begin{array}{l}\text { Classes } \\
\text { mapeadas }\end{array}$} & \multicolumn{2}{|c|}{1985} & \multicolumn{2}{c|}{2000} & \multicolumn{2}{c}{2015} \\
\cline { 2 - 7 } & $\begin{array}{l}\text { Área em } \\
\text { (ha) }\end{array}$ & $\begin{array}{l}\text { \% em } \\
\text { relação à } \\
\text { área total }\end{array}$ & $\begin{array}{l}\text { Área em } \\
\text { (ha) }\end{array}$ & $\begin{array}{l}\text { \% em } \\
\text { relação à } \\
\text { área total }\end{array}$ & $\begin{array}{l}\text { Área em } \\
\text { (ha) }\end{array}$ & $\begin{array}{l}\text { \% em } \\
\text { relação à } \\
\text { área total }\end{array}$ \\
\hline Água & 105,21 & 1 & 124,11 & 1 & 141,55 & 1 \\
\hline Nuvens & 19,98 & 0 & 19,36 & 0 & 13,14 & 0 \\
\hline $\begin{array}{l}\text { Solo } \\
\text { exposto }\end{array}$ & 3352,46 & 21 & 708,82 & 7 & 1125,36 & 7 \\
\hline Urbano & 944,17 & 6 & 1100,50 & 4 & 1046,32 & 6 \\
\hline Vegetação & 11707,91 & 72 & 14176,95 & 88 & 13803,35 & 86 \\
\hline
\end{tabular}

Fonte: Araújo (2019).

Figura 6 - Percentual em relação à área total das classes estudadas no Corredor Ecológico do Rio Pacoti

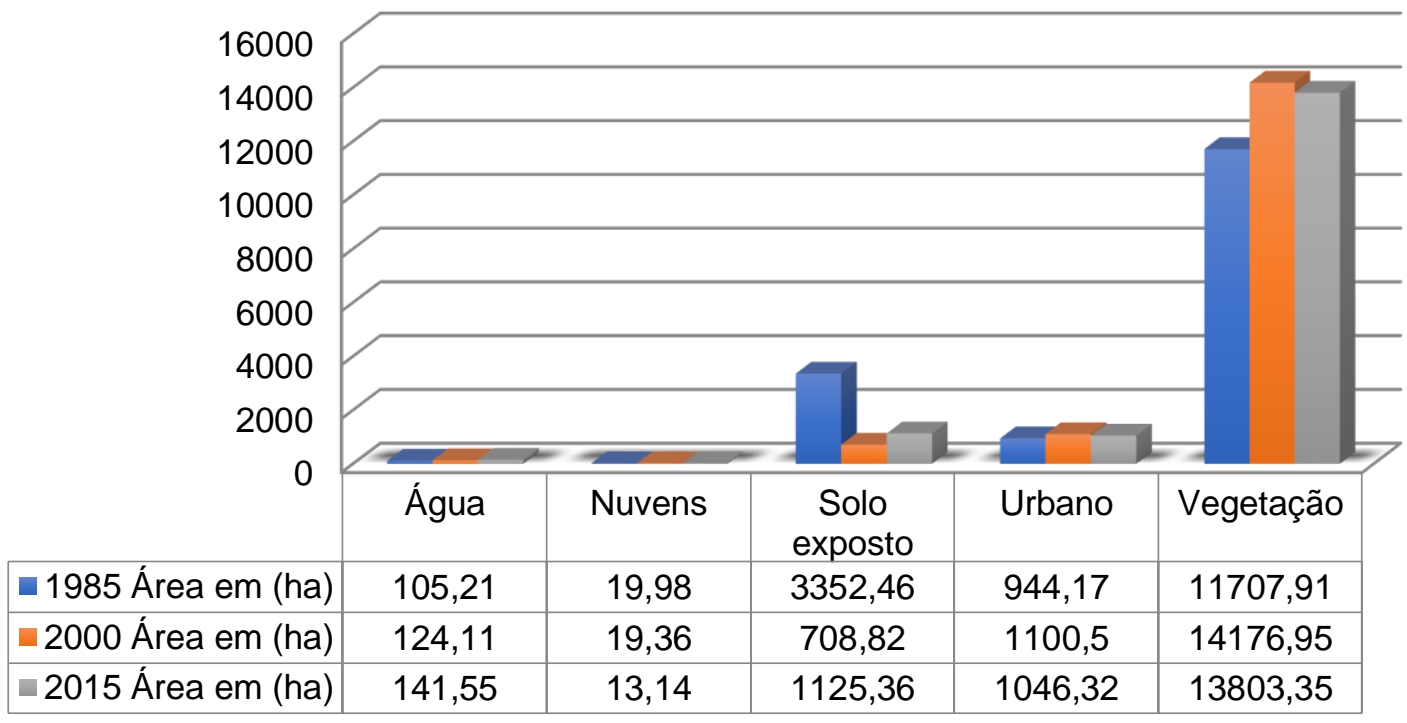

Fonte: Araújo (2019). 
Apesar do ano de 1985 ter apresentado índices de precipitação maiores que as normais para o Estado do Ceará, considerado, portanto, um ano chuvoso, a resposta da vegetação do corredor não foi a esperada.

Já entre os anos de 2000 para 2015, o solo exposto teve uma variação de apenas $2,58 \%$. No entanto, a variação da classe Urbano de 1985 para 2000 foi de $0,97 \%$ e de 2000 para 2015 variou de $0,34 \%$. Ficou perceptível o aumento da mancha urbana, principalmente nos municípios de Acarape, Redenção, Itaitinga e Aquiraz. No setor oeste do corredor, a ocupação do solo aconteceu de forma diferente do setor leste. O setor leste, onde se localiza os municípios de Itatinga e Aquiraz, os quais a ocupação urbana teve uma representação considerável, seguiram a ocupação da Região Metropolitana de Fortaleza.

A classe Água, nesse e nos mapeamentos que se seguiram referentes aos anos estudados, apresentou baixa representatividade $(<1 \%)$ da área total do corredor. É importante considerar que para a aplicação da classificação supervisionada foi utilizada a delimitação atual do Decreto n ⒊164, de 02 de março de 2017 (CEARÁ, 2017a), a qual não inclui os espelhos d'água do Açude Acarape e do Açude Riachão na sua delimitação, justificando a baixa representatividade desta classe. No corredor ecológico foi possível identificar dois principais vetores de pressão humana os quais serão descritos a seguir: mineração e expansão urbana.

A mineração é uma das atividades humanas que mais acarreta alterações na superfície terrestre causando degradação visual da paisagem, do solo, do relevo, e inclusive das populações que habitam o entorno dos projetos minerários. Segundo Pena et al. (2017) e Sonter, Herrera e Barret (2017), a mineração é responsável por grande perda da biodiversidade, uma vez que causa supressão e fragmentação de hábitats. Atividades como agricultura, pecuária, urbanização e, principalmente, a mineração são os maiores agentes de mudança para a aceleração da transformação do uso do solo e da alteração da paisagem. As principais alterações ambientais provocadas pela mineração são a supressão da vegetação, a mudança da superfície topográfica, o impacto visual, a indução de escorregamentos, a destruição da fauna, o assoreamento de cursos d'água e a mudança no nível freático (BITAR, 1997).

Apesar de ter havido uma diminuição da classe solo exposto entre os anos escolhidos para análise, pode-se destacar a mineração (predominantemente extração de areia e argila) como um dos vetores de pressão que possui uma relevante contribuição na degradação ambiental do corredor ecológico e diminuição da conectividade e sustentabilidade. Localizada no Médio e Baixo curso do Rio Pacoti, nos municípios de Itaitinga e Aquiraz, essa atividade predomina apresentando uma acentuada problemática ambiental proporcionada pela atividade já que a mesma interfere direta e indiretamente sobre as características ambientais da área como a remoção da cobertura vegetal (Figura 7). 
Figura 7 - Atividade de extração mineral no município de Aquiraz

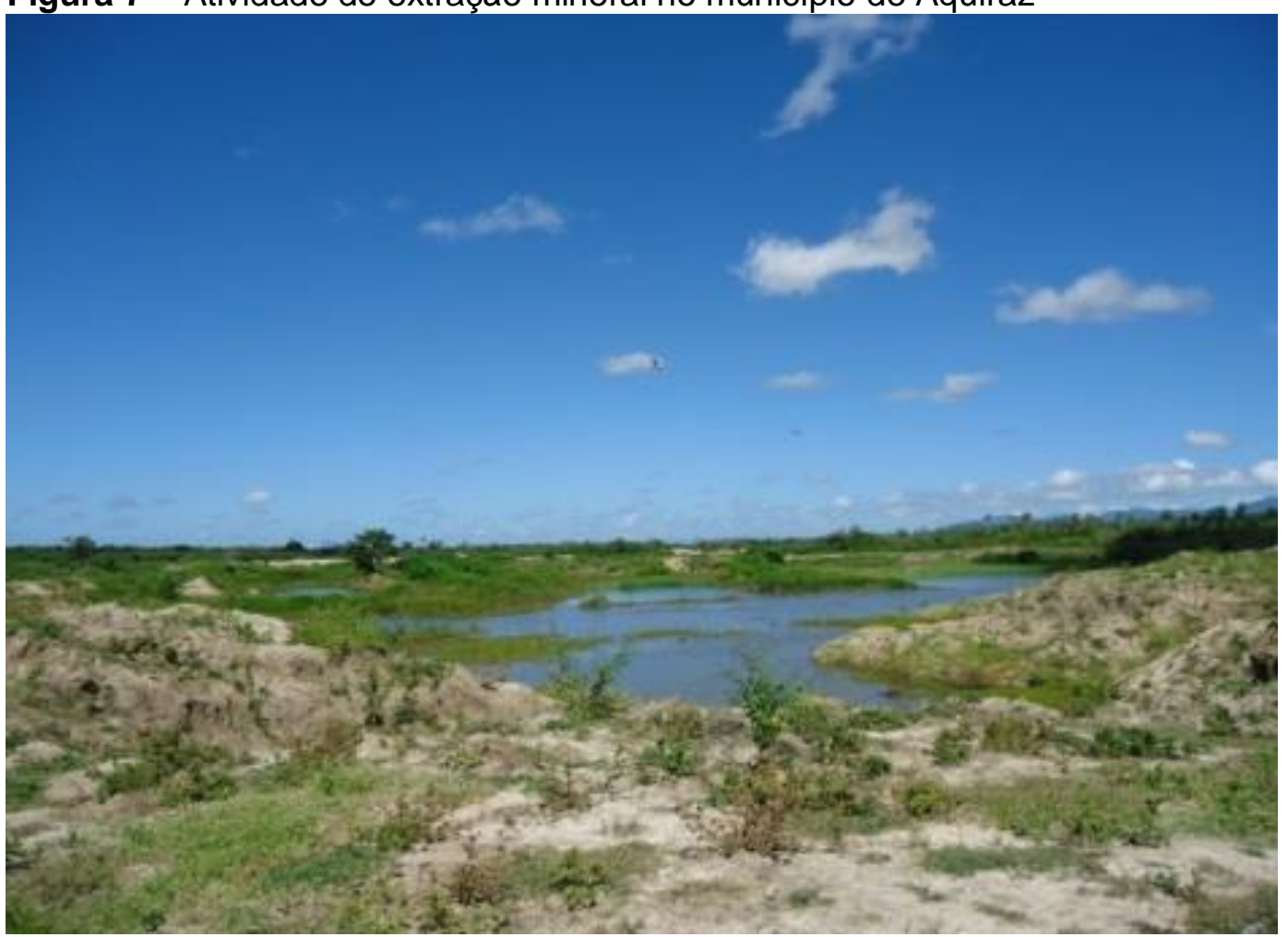

Fonte: Ceará (2017b).

De acordo com o artigo $5^{\circ}$ do Código de Mineração, "[...] a atividade de mineração abrange a pesquisa, a lavra, o desenvolvimento da mina, o beneficiamento, a comercialização dos minérios, o aproveitamento de rejeitos e estéreis e o fechamento da mina" (BRASIL, 2018).

Com a regulamentação do Novo Código Florestal a atividade minerária em áreas de preservação permanente tornou-se possível, desde que observado certas ressalvas. Segundo o que se apresenta no artigo $8^{\circ}$ desta mesma lei, a intervenção ou a supressão de vegetação nativa em área de preservação permanente somente ocorrerá nas hipóteses de utilidade pública social, de interesse social ou de baixo impacto ambiental (BRASIL, 2012).

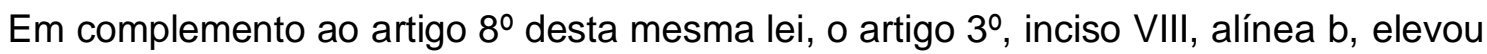
à condição de utilidade pública a atividade minerária. O inciso IX, alínea f, elevou ao grau de interesse social as atividades de pesquisa e extração de areia, argila, saibro e cascalho, outorgadas pela autoridade competente (BRASIL, 2012).

De acordo com Santos (2008), a extração de areia ocorre nos seguintes depósitos minerais: sedimentos inconsolidados quaternários, planícies fluviais, rochas sedimentares cenozoicas e mantos de alteração de rochas pré-cambrianas. No Brasil, "[...] 70\% da areia é produzida e extraída em leito de rios e 30\% nas várzeas" (VALVERDE, 2006, p. 37). 
Almeida e Sánchez (2005) afirmam que a areia é retirada principalmente nas várzeas aluvionares, resultando em processos de degradação do meio físico, principalmente do solo. No ano de 1989 foi estabelecida no Brasil uma exigência em que todas as empresas de mineração são obrigadas a apresentar ao órgão ambiental um Plano de Recuperação de Áreas Degradadas (PRAD). Este documento recomenda que sejam adotados procedimentos de revegetação da cobertura vegetal nas áreas que foram degradadas. De acordo com o $\S$ $1^{\circ}$, do artigo $7^{\circ}$, do Novo Código Florestal, tendo ocorrido supressão de vegetação situada em área de preservação permanente, o proprietário da área, possuidor ou ocupante a qualquer título, é obrigado a promover a recomposição da vegetação. (BRASIL, 2012).

Dessa forma, pode-se verificar (Quadro 2) que há 40 processos minerários cadastrados no órgão entre os anos de 1995 a 2019 na área de estudo. Dentre esses catalogados, trinta e cinco são de extração de areia, a maioria licenciado ou em processo de licenciamento, três autorizações de pesquisa para minério de manganês e uma para argila e um dado não cadastrado no ano de 2016.

A maior quantidade de processos licenciados ou em processo de licenciamento para extração de areia foi observado entre os anos de 1995 a 2008 não ultrapassando a 50 hectares de área e utilizado para uso na construção civil em sua maioria. No mapa a seguir (Figura 8) verifica-se a distribuição das atividades de mineração na área de estudo.

A expansão urbana é também uma atividade humana que pode ser considerada de alto impacto para o aumento da fragmentação. Concentrando-se nos municípios de Redenção, Acarape, Aquiraz e Itaitinga, o crescimento urbano tem gerado uma série de impactos que comprometerá a conectividade funcional de ambientes terrestres e aquáticos, principalmente quando se observa que a expansão urbana não respeita os limites de preservação impostos pelas Áreas de Preservação Permanente do Rio Pacoti (Figura 9).

Embora os resultados apresentados evidenciem um aumento da vegetação na área delimitada do corredor, é possível observar, por meio das imagens de satélite, que as zonas ripárias, de várzea ou mata ciliar, sofrem com o impacto dessas atividades havendo a descontinuidade dessa fitofisionomia. As matas ciliares fazem exatamente o papel do corredor de habitat. Trata-se de uma área com a combinação apropriada de recursos (alimento, abrigo) e condições ambientais para a reprodução e sobrevivência das espécies. Se um corredor não propicia um habitat apropriado, não facilitará também a dispersão (KORMAN, 2003).

Sobre a ruptura da continuidade dos ecossistemas florestais, Soulé (1991) afirma que o processo de fragmentação pode ser um dos fatores principais para a diminuição da conectividade da paisagem. Ao diminuir a área entre os ecossistemas esses processos restringirão as possibilidades de recolonização e aumentam os riscos de extinção local das espécies e, dessa forma, ameaçam de forma direta a manutenção da biodiversidade (Figura 10). 
Quadro 2 - Atividades de mineração realizadas no Corredor Ecológico do rio Pacoti entre os anos de 1995 a 2019

\begin{tabular}{|c|c|c|c|c|}
\hline ANO & ÁREA (HA) & FASE & SUBSTRATO & USO \\
\hline 1995 & 37,48 & Requerimento de licenciamento & Areia & Não informado \\
\hline 1996 & 50 & Licenciamento & Areia & Construção civil \\
\hline 1996 & 50 & Licenciamento & Areia & Construção civil \\
\hline 1996 & 50 & Licenciamento & Areia & Construção civil \\
\hline 1996 & 50 & Licenciamento & Areia & Construção civil \\
\hline 1996 & 50 & Licenciamento & Areia & Construção civil \\
\hline 1996 & 50 & Licenciamento & Areia & Construção civil \\
\hline 1996 & 50 & Licenciamento & Areia & Construção civil \\
\hline 1996 & 50 & Licenciamento & Areia & Construção civil \\
\hline 1996 & 49,96 & Licenciamento & Areia & Construção civil \\
\hline 1996 & 48,99 & Licenciamento & Areia & Construção civil \\
\hline 2003 & 24,15 & Licenciamento & Areia & Construção civil \\
\hline 2006 & 47,08 & Licenciamento & Areia & Construção civil \\
\hline 2008 & 15,8 & Licenciamento & Areia & Construção civil \\
\hline 2008 & 48,96 & Licenciamento & Areia & Construção civil \\
\hline 2008 & 49,87 & Licenciamento & Areia & Construção civil \\
\hline 2009 & 1999,94 & Autorização de pesquisa & Minério de Manganês & Industrial \\
\hline 2009 & 1726,43 & Autorização de pesquisa & Minério de Manganês & Industrial \\
\hline 2011 & 957,1 & Autorização de pesquisa & Argila & Industrial \\
\hline 2012 & 10,02 & Requerimento de licenciamento & Areia & Construção civil \\
\hline 2012 & 49,77 & Requerimento de licenciamento & Areia & Construção civil \\
\hline 2013 & 49,4 & Licenciamento & Areia & Construção civil \\
\hline 2013 & 47,5 & Licenciamento & Areia & Construção civil \\
\hline 2013 & 6,9 & Licenciamento & Areia & Construção civil \\
\hline 2014 & 4,4 & Disponibilidade & Areia & Construção civil \\
\hline 2015 & 47,25 & Licenciamento & Areia & Construção civil \\
\hline 2015 & 955,56 & Autorização de pesquisa & Minério de Manganês & Industrial \\
\hline 2015 & 7,24 & Requerimento de licenciamento & Areia & Construção civil \\
\hline 2015 & 49,01 & Requerimento de licenciamento & Areia & Construção civil \\
\hline 2015 & 40,71 & Requerimento de licenciamento & Areia & Construção civil \\
\hline 2016 & 48,72 & Autorização de pesquisa & Areia & Construção civil \\
\hline 2016 & 43,83 & Requerimento de licenciamento & Areia & Construção civil \\
\hline 2016 & 107,33 & Disponibilidade & Dado não cadastrado & Dado não cadastrado \\
\hline 2016 & 5,13 & Requerimento de licenciamento & Areia & Construção civil \\
\hline 2017 & 13,82 & Licenciamento & Areia & Construção civil \\
\hline 2017 & 50 & Requerimento de licenciamento & Areia & Construção civil \\
\hline 2017 & 5,42 & Requerimento de licenciamento & Areia & Construção civil \\
\hline 2018 & 15,15 & Requerimento de licenciamento & Areia & Construção civil \\
\hline 2018 & 30,63 & Requerimento de pesquisa & Areia & Construção civil \\
\hline 2019 & 18,48 & Autorização de pesquisa & Areia & Construção civil \\
\hline
\end{tabular}

Fonte: Agência Nacional de Mineração (2019). 
Figura 8 - Mapa das atividades de mineração localizadas no Corredor Ecológico do rio Pacoti - CE

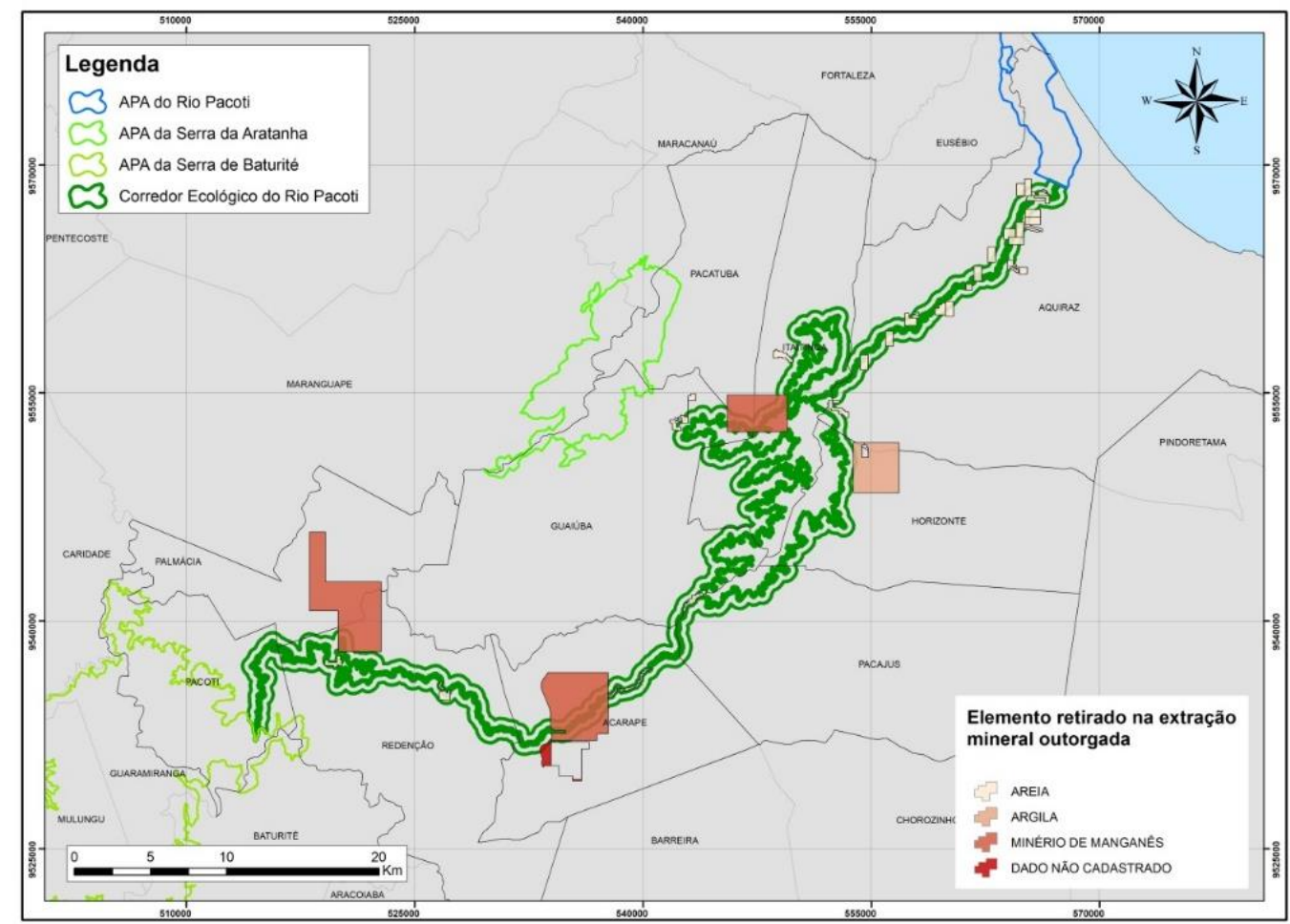

Fonte: Araújo (2019) e Agência Nacional de Mineração (2019).

Figura 9 - Sede urbana de Redenção, situada especialmente na planície fluvial do Rio Pacoti. Exemplo de área urbana consolidada na área do Corredor Ecológico

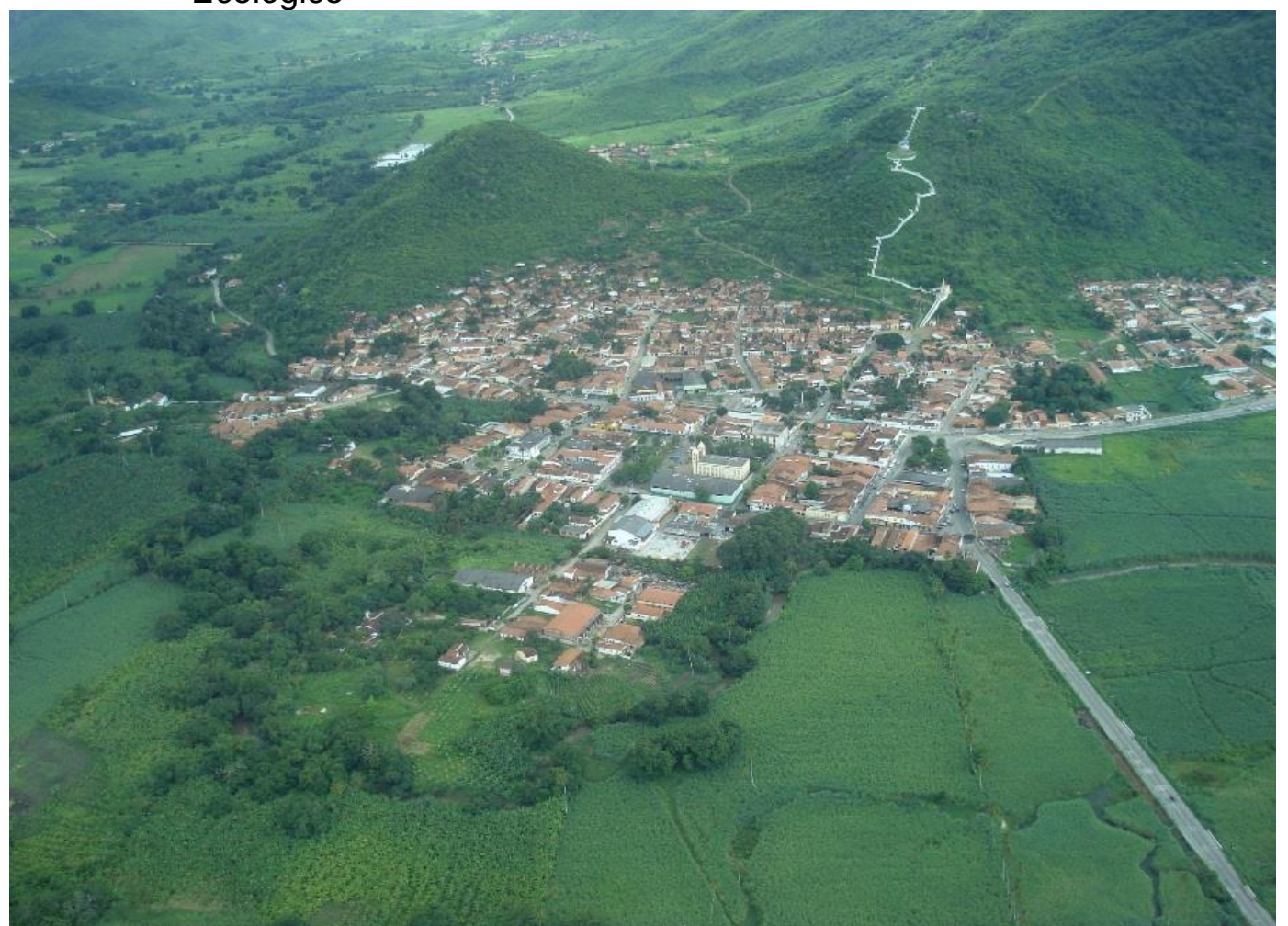

Fonte: Bastos (2012). 
Figura 10 - Barragem do açude do rio Pacoti, responsável pela inundação de uma área de 3.700,000 hectares e causou expressivo impacto na biota

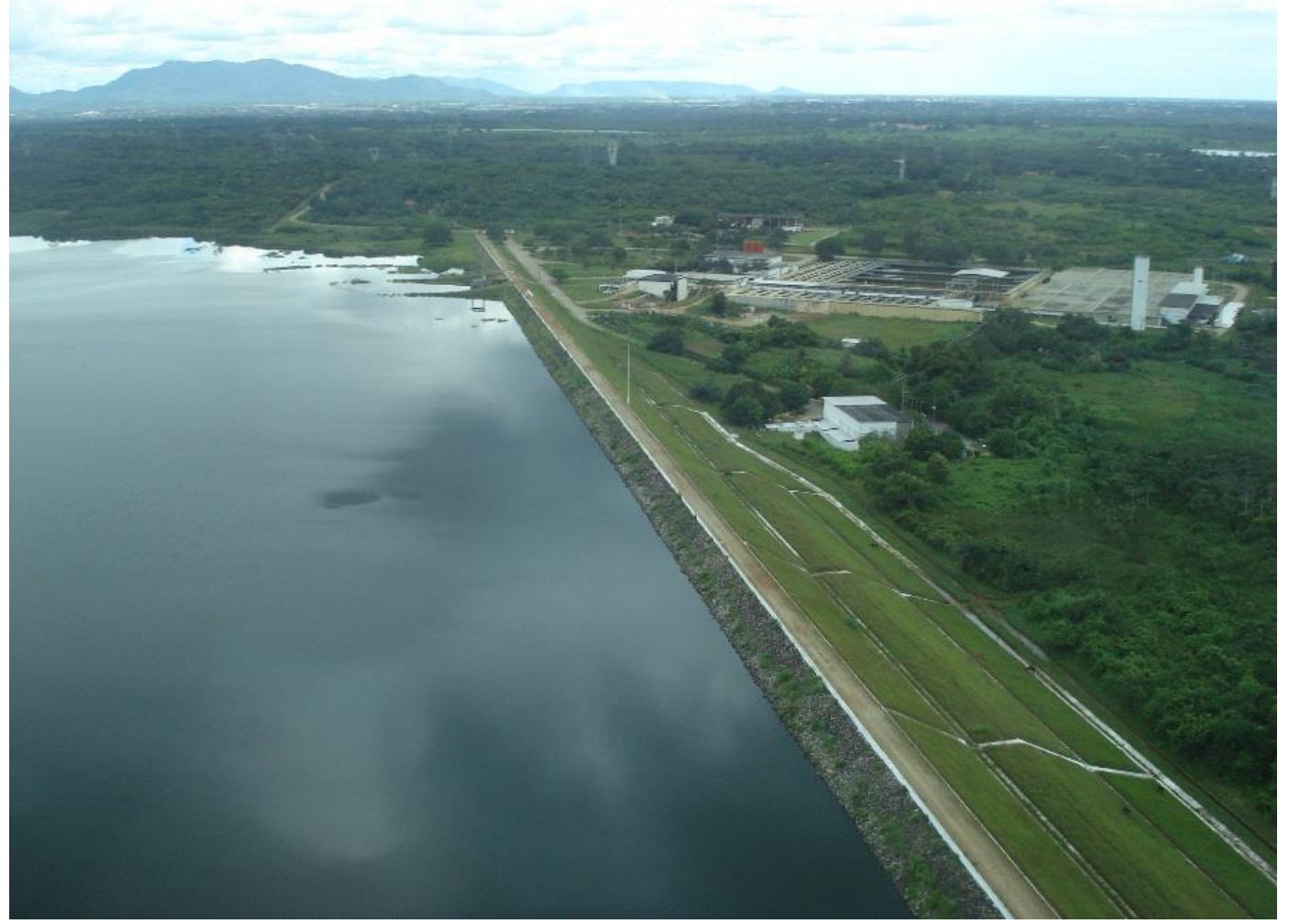

Fonte: Bastos (2012).

Tendo em vista o mapeamento da evolução das formas de uso e ocupação do corredor, pode-se perceber que é imprescindível que haja um ordenamento territorial nas áreas em que não se respeita a legislação pertinente. Nas áreas onde ocorre solo exposto, e nas classes onde há aumento da classe urbano, a maioria está localizada em Áreas de Preservação Permanente - APP (Figura 11). Essas áreas próximas ao rio têm alta diversidade de espécies e se comportam como corredores de dispersão naturais, conectando diferentes tipos de ambientes sendo prioritárias para a conservação e manutenção do equilíbrio ambiental (RANZINI et al., 2004).

Segundo Haddad (1999), corredores dentro de qualquer paisagem têm efeitos positivos, negativos ou neutros para diferentes espécies, pois sua eficácia é específica para as espécies e a paisagem. É importante monitorar o fluxo de organismos e o uso do solo na região-alvo, para se avaliar como as diferentes espécies (especialistas e generalistas) estão respondendo às alterações na configuração da paisagem provocadas pela implantação de corredores florestais.

Dessa maneira, o mapeamento e estudo da evolução do uso da terra/cobertura vegetal, mediante a utilização de técnicas de geoprocessamento, representa importante instrumento para o planejamento da conservação ambiental possibilitando a avaliação e o monitoramento, 
pois empregam tecnologias mais adequadas, para detectar a expansão urbana e as alterações ambientais decorrentes, contribuindo para maior eficiência da ação dos órgãos de planejamento (FARINA, 2006).

Figura 11 - Desrespeito às areas de preservação permanente - APPs. Ocupação nas margens do rio Pacoti, município de Redenção - CE

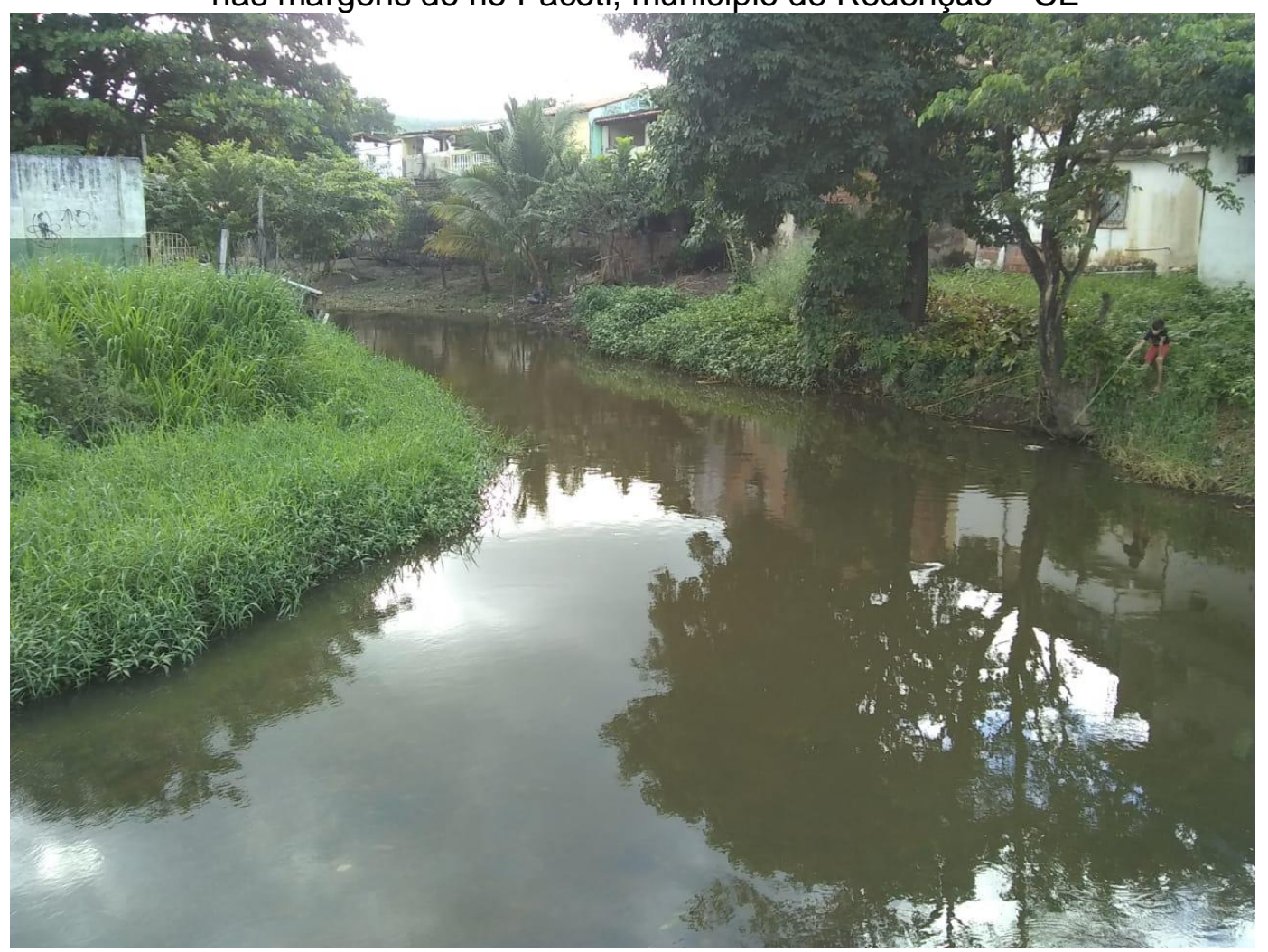

Fonte: Araújo (2019).

\section{CONCLUSÕES}

A utilização de técnicas de processamento digital de imagens orbitais mostrou-se eficiente na estimativa da dinâmica temporal do uso e ocupação da terra. Analisando os resultados obtidos a partir do processamento das imagens e elaboração dos mapas de uso e cobertura do solo do Corredor Ecológico do Rio Pacoti para os anos de 1985, 2000 e 2015 foi possível observar mudanças significativas nas tipologias mapeadas, principalmente vegetação e solo exposto. Constatou-se um aumento das áreas de vegetação nativa no ano 2000 e uma diminuição considerável das áreas destinadas ao solo exposto.

Pode-se afirmar que, de modo geral, houve melhoria nos níveis de proteção vegetal na área de estudo entre os anos analisados. Isto ocorreu provavelmente devido a ocorrência de uma possível sucessão ecológica secundária, que se refletiu em melhoras na condição ambiental e que permitiu a identificação de crescimento de áreas florestadas. Apesar do ano de 1985 ter apresentado índices de precipitação maiores que as normais para o Estado do 
Ceará, considerado, portanto, um ano chuvoso, a resposta da vegetação do corredor não foi a esperada.

\section{REFERÊNCIAS}

AGÊNCIA NACIONAL DE MINERAÇÃO - ANM. Sistema de Informações Geográficas da Mineração - SIGMINE. Disponível em: http://www.anm.gov.br/assuntos/aominerador/sigmine. Acesso em: 8 jul. 2019.

ALMEIDA, R. O. P. O.; SÁNCHEZ, L. E. Revegetação de áreas de mineração: critérios de monitoramento e avaliação do desempenho. Revista Árvore, Viçosa, v. 29, n. 1, p. 47-54, 2005. Disponível em: http://www.scielo.br/scielo.php?script=sci_arttext\&pid=S010067622005000100006. Acesso em: 23 abr. 2018.

ARAÚJO, T. M. S. Dinâmica e evolução da paisagem do corredor ecológico do rio Pacoti - CE. 2019. Tese (Doutorado em Geografia). Centro de Ciência e Tecnologia, Universidade Estadual do Ceará, Fortaleza, 2019. Disponível em:

http://www.uece.br/mag/dmdocuments/thatiane_maria_souzade_araujo.pdf. Acesso em: 2 abr. 2020.

BASTOS, F. de H. Movimentos de massa no Maciço de Baturité (CE) e contribuições para estratégias de planejamento ambiental. 2012. Tese (Doutorado em Geografia) Centro de Ciências, Universidade Federal do Ceará, Fortaleza, 2012. Disponível em: http://www.repositorio.ufc.br/handle/riufc/7850. Acesso em: 2 maio 2017.

BASTOS, F. de H.; CORDEIRO, A. M. N.; SILVA, E. V. da. Aspectos geoambientais e contribuições para estratégias de planejamento ambiental da Serra de Baturité/CE. Revista da ANPEGE, João Pessoa, PB, v.3. n. 21, p. 163-198, 2017. Disponível em: http://ojs.ufgd.edu.br/index.php/anpege/article/view/6947. Acesso em: 16 mar. 2018.

BÉTARD, F.; PEULVAST, J.-P.; CLAUDINO-SALES, V. Caracterização morfopedólogica de uma serra úmida no semi-árido do nordeste brasileiro: o caso do maciço de Baturité-CE. Mercator, Fortaleza, CE, v. 6, n. 12, p. 107-126, 2007. Disponível em: http://www.mercator.ufc.br/mercator/article/view/49. Acesso em: 28 nov. 2018.

BITAR, O. Y. Avaliação da recuperação de áreas degradadas por mineração na região metropolitana de São Paulo.1997. $185 \mathrm{f}$. Tese (Doutorado em Engenharia) - Escola Politécnica, Departamento de Engenharia de Minas, Universidade de São Paulo, São Paulo, 1997. Disponível em: https://www.teses.usp.br/teses/disponiveis/3/3134/tde-25102001165349/publico/Tese.PDF. Acesso em: 8 fev. 2018.

BRASIL. Decreto no 9.406, de 12 de junho de 2018. Regulamenta o Decreto-Lei oㅡ 227, de 28 de fevereiro de 1967, a Lei oㅜ 6.567, de 24 de setembro de 1978, a Lei no 7.805, de 18 de julho de 1989, e a Lei no 13.575, de 26 de dezembro de 2017. Diário Oficial da União: seção 1, Brasília, DF, ano 155, n. 112, p. 1, 13 jun. 2018. Disponível em: http://pesquisa.in.gov.br/imprensa/jsp/visualiza/index.jsp?data=13/06/2018\&jornal=515\&pagi na=1. Acesso em: 5 ago. 2019.

BRASIL. Lei no 12.651, de 25 de maio de 2012. Institui o Novo Código Florestal Brasileiro. Brasília, DF: Presidência da República, 2012. Disponível em:

https://presrepublica.jusbrasil.com.br/legislacao/1032082/lei-12651-12. Acesso em: 25 abr. 2016.

CAVALCANTE, A. M. B. Jardins suspensos no Sertão. Scientific American Brasil, São Paulo, SP, v. 3, n. 32, p. 69-73, 2005. Disponível em: http://sciam.uol.com.br/jardinssuspensos-no-sertao/. Acesso em: 23 abr. 2018.

CEARÁ. Decreto no 32.164, de 02 de março de 2017. Altera o Decreto no 25.777 , de 15 de fevereiro de 2000, que dispõe sobre a poligonal do Corredor Ecológico do Rio Pacoti, e dá 
outras providências. 2017. Diário Oficial do Estado do Ceará: Poder Executivo, Fortaleza, p. 253, 6 mar. 2017a. Disponível em: https://www.jusbrasil.com.br/diarios/139176331/doece06-03-2017-pg-253. Acesso em: 5 jan. 2018.

CEARÁ. Secretaria do Meio Ambiente. Acervo fotográfico. Fortaleza, CE: SEMA, 2017.

CRÓSTA, A. P. Processamento digital de imagens de sensoriamento remoto.

Campinas, SP: IG/UNICAMP, 1992.

FARINA, F. C. Abordagem sobre as técnicas de geoprocessamento aplicadas ao planejamento e gestão urbana. Caderno da EBAPE. BR, Rio de Janeiro, v. 4, n. 4, p. 1-13, 2006. Disponível em: http://www.scielo.br/scielo.php?script=sci_arttext\&pid=S167939512006000400007\&lng=en\&nrm=iso. Acesso em: 2 abr. 2020.

HADDAD, N. M. Corridor and distance effects on interpatch movements: a landscape experiment with butterflies. Ecological Applications, Washington, US, v. 9, n. 2, p. 612 622, 1999. Disponível em: https://esajournals.onlinelibrary.wiley.com/doi/10.1890/1051 0761(1999)009[0612:CADEOI]2.0.CO;2. Acesso em: 12 jun. 2018.

IBGE. Manual técnico de uso da terra. Rio de Janeiro: IBGE, 1999. Disponível em: https://biblioteca.ibge.gov.br/visualizacao/livros/liv8199.pdf. Acesso em: 4 jun. 2018.

IBGE. Manual técnico de uso da terra. Rio de Janeiro: Ministério do Planejamento, Orçamento e Gestão, 2013. Disponível em:

https://biblioteca.ibge.gov.br/visualizacao/livros/liv81615.pdf. Acesso em: 4 maio 2018.

INSTITUTO NACIONAL DE PESQUISAS ESPACIAIS - INPE. Divisão de Geração de Imagens. Disponível em: http://www.dgi.inpe.br/documentacao/satelites/landsat. Acesso em: 5 ago. 2019.

KORMAN, V. Proposta de interligação das glebas do parque estadual de Vassununga (Santa Rita do Passa Quatro, SP). 2003. Dissertação (Mestrado em Ecologia de Agroecossistemas) - Universidade de São Paulo, Piracicaba, SP, 2003. Disponível em: doi:10.11606/D.91.2003.tde-24062005-103324. Acesso em: 3 fev. 2018.

NIMER, E. Circulação atmosférica do Nordeste e suas consequências o fenômeno das secas. Revista Brasileira de Geografia, Rio de Janeiro, RJ, v. 34, n. 4, p. 3-28, 1972.

NOVELLI, F. Z.; SILVA, A. G. As áreas de preservação permanente como evidências de conectividade de fragmentos florestais no Corredor Ecológico Duas Bocas - Mestre Álvaro. Natureza on-line, Santa Teresa, ES, v. 11 n. 3, p. 102-117, 2013. Disponível em: http://www.naturezaonline.com.br/natureza/conteudo/pdf/01_Novelli\&Silva_102117.pdf. Acesso em: 10 maio 2018.

NOVO, E. L. M. Sensoriamento remoto: princípios e aplicações. São Paulo: Edgar Blücher, 2008.

PENA, J. C. C.; GOULART, F.; HOFFMAN, D.; LEITE, F. S. F.; SANTOS, N. B.; SOARES FILHO, B.; SOBRAL-SOUZA, T.; VANCINE, M. H.; RODRIGUES, M. Impacts of mining activities on the potential geographic distribution of eastern Brazil mountaintop endemic species. Perspectives in Ecology and Conservation, Amsterdam, v. 15, n. 3, p. 172-178, 2017. Disponível em:

https://www.sciencedirect.com/science/article/pii/S167900731630130X. Acesso em: 6 maio 2018.

PRADO, R. B.; NOVO, E. M. L. M.; PEREIRA, M. N. Avaliação da dinâmica do uso e cobertura da terra na bacia hidrográfica de contribuição para o reservatório de barra bonita SP. Revista Brasileira de Cartografia, Rio de Janeiro, RJ, v. 59, n. 2, 11, p. 127-135, 2007. Disponível em:

http://www.seer.ufu.br/index.php/revistabrasileiracartografia/article/view/44898. Acesso em: 3 jul. 2018. 
RANZINI, M.; RIGUETTO, A. M.; LIMA, W. de P.; GUANDIQUE, M. E. G.; ARCOVA, F. C. S.; CICCO, V. de. Processos hidrológicos de uma microbacia com Mata Atlântica, na região da Serra do Mar, SP. Scientia Forestalis, Piracicaba, SP, n. 66, p. 108-119, 2004.

Disponível em: https://www.ipef.br/publicacoes/scientia/nr66/cap11.pdf. Acesso em: 16 fev. 2019.

SANTOS, D. N. Extração de areia e a dinâmica sedimentar no alto curso do Rio Paraná na Região de Porto Rico, PR. Dissertação. 2008. (Mestrado em Geociências e Meio Ambiente) - Departamento de Geociências, Universidade Guarulhos, Guarulhos, SP, 2008.

SONTER, L. J.; HERRERA, D., BARRET, D. J. Mining drives extensive deforestation in the Brazilian Amazon. Nature Communications, London, UK, v. 8, n. 1013, p. 1-7, 2017. Disponível em: https://doi.org/10.1038/s41467-017-00557-w. Acesso em: 10 mar. 2019.

SOULÉ, E. M. Conservation: tactics for a constant crisis. Science, Washington, DC, v. 253, n. 5021, p. 744-750, 1991. Disponível em:

https://science.sciencemag.org/content/253/5021/744. Acesso em: 9 abr. 2018.

VALVERDE, F. M. Agregados para construção civil. In: BRASIL. Departamento Nacional de Produção Mineral. Sumário mineral brasileiro. Brasília: DNPM, 2006. p. 37-42.

Recebido: novembro de 2019. Aceito: abril de 2020. 